\title{
Infectivity Titration of Guinea-pig Inclusion Conjunctivitis Agent in Irradiated McCoy Cells
}

\author{
By M. S. GRIFFITHS, S. AINSWORTH AND J. H. PEARCE \\ Department of Microbiology, University of Birmingham, Birmingham BI5 $2 T T$
}

(Received Io February 1976)

\begin{abstract}
SUMMARY
Estimation of the infectivity of the agent of guinea-pig inclusion conjunctivitis for irradiated McCoy cells, assayed as inclusion-forming units, was influenced by the age of cells after irradiation, the maturation time of the inclusions, the centrifugal force and the centrifugation temperature. Agent passaged through irradiated McCoy cells or guinea-pig conjunctivae showed a greater capacity to infect irradiated McCoy cells without centrifuging than agent grown in a chick embryo. The nature of the change and the mechanism of infectivity enhancement by centrifuging are discussed.
\end{abstract}

\section{INTRODUCTION}

Chlamydia psittaci, strain guinea-pig inclusion conjunctivitis (gp-ic), causes acute, selflimiting infections of the conjunctiva (Murray, 1964) and genital tract (Mount, Bigazzi \& Barron, 1972) only in guinea pigs. Current interest in gp-ic infection arises because of its value as a model for chlamydial ( $C$. trachomatis) infection of the conjunctiva and genital tract in man (Murray, Charbonnet \& MacDonald, I973; Mount et al., 1972). Gp-ic was originally isolated and is usually titrated for infectivity in embryonated eggs, although many chlamydiae may be titrated as inclusion-forming units (i.f.u.) in cell cultures. A cell culture assay for gp-ic has not been described, although, if as sensitive as that in eggs, it would have advantages in speed, accuracy and reduced cost.

Treharne (1971) described the formation of inclusions after centrifuging gp-ic on to irradiated McCoy cells, and showed that the latter were of the same order of sensitivity as eggs for isolating the agent from infected conjunctivae.

We report here the quantitative measurement of gp-ic infectivity as i.f.u. in irradiated McCoy cells. Extensive work on the isolation of chlamydiae from clinical material, using irradiated McCoy cells, has shown the influence on isolation rate of such factors as centrifugal force and temperature and time of centrifugation during inoculation of organisms on to cells (Darougar et al., I972). We have examined the effect of cell age, centrifugal force, temperature, adsorption time and growth cycle time on the sensitivity of measurement of gp-ic infectivity.

\section{METHODS}

Organisms. The agent of guinea-pig inclusion conjunctivitis (gp-ic) and the fast eggkilling variant, MRC4f, of trachoma and inclusion conjunctivitis (TRIC/E/GB/MRC4/ON) were grown in eggs, harvested and purified (Moore, Griffiths \& Pearce, 1974). Purified organisms were stored at $-70^{\circ} \mathrm{C}$. Gp-ic from an infected guinea-pig conjunctiva was obtained in conjunctival scrapings and released by shaking with glass beads in Hanks balanced salts solution (Gibco-Biocult, Paisley, Renfrew) containing $10 \%(\mathrm{v} / \mathrm{v})$ foetal bovine serum 
(Gibco-Biocult). The conjunctival scrapings were taken under nembutal anaesthesia from a guinea-pig infected 5 days earlier with yolk-sac-grown gp-ic.

McCoy cell cultures. Cells were from the Institute of Ophthalmology, London or from Flow Laboratories (Irvine, Ayrshire). They were cultured in flasks $\left(7500 \mathrm{~mm}^{2}\right.$; Falcon brand; Becton, Dickinson UK, Wembley, Middlesex) in growth medium at $35^{\circ} \mathrm{C}$ in air/ $\mathrm{CO}_{2}(95: 5, \mathrm{v} / \mathrm{v})$ until confluent. Growth medium was Eagle's MEM (Gibco-Biocult), with glutamine, buffered with Earle's balanced salts solution_(Gibco-Biocult) and supplemented with $10 \%(\mathrm{v} / \mathrm{v})$ heated $\left(56^{\circ} \mathrm{C} ; 60 \mathrm{~min}\right)$ foetal bovine serum, streptomycin ( $\left.100 \mu \mathrm{g} \mathrm{ml}^{-1}\right)$ and vancomycin $\left(100 \mu \mathrm{g} \mathrm{ml}^{-1}\right)$. Cells were passaged and harvested as described by Darougar et al. (1972).

Irradiation of McCoy cells and monolayer preparation. Suspensions containing approx. $2 \times 10^{6}$ cells $\mathrm{ml}^{-1}$ were subjected to $5000 \mathrm{rad} \mathrm{X}$-irradiation (Pantak special $300 \mathrm{kV}$ X-ray unit; Pantak, Windsor, Berkshire), hardened by passage through a $0.17 \mathrm{~mm}$-thick copper filter (half value thickness, $\mathrm{I} \cdot 5 \mathrm{~mm}$ ). After irradiation, suspensions were diluted to $10^{5}$ cells $\mathrm{ml}^{-1}$ in growth medium and $\mathrm{I} \mathrm{ml}$ portions were inoculated into plastic bottles (Bijou, $7 \mathrm{ml}$; Sterilin, Richmond, Surrey) containing $13 \mathrm{~mm}$ diam. coverslips (no. I thickness; Chance Propper, Smethwick, Worcestershire) which had been soaked in Lipsol (Laboratory, Industrial and Pharmaceutical Services, Shipley, Yorkshire), thoroughly rinsed in distilled water and stored under methanol. The cell monolayers were incubated at $35^{\circ} \mathrm{C}$ in air/ $\mathrm{CO}_{2}$ $(95: 5, v / v)$ until use 4 to 8 days later.

Titration of gp-ic infectivity in irradiated McCoy cells. Dilutions of gp-ic in Hanks balanced salts solution containing $10 \%(\mathrm{v} / \mathrm{v})$ foetal bovine serum were inoculated $(0.2 \mathrm{ml})$ on to three replicate monolayers from which the growth medium had been removed. The monolayers (in Bijou bottles) were centrifuged for $60 \mathrm{~min}$ at $2150 \mathrm{~g}$ and $35^{\circ} \mathrm{C}$, unless otherwise stated, in a Mistral 6L centrifuge (M.S.E., Crawley, Sussex). In certain experiments, for forces above $2150 \mathrm{~g}$, an M.S.E. High speed $\mathrm{I} 8$ centrifuge with an $8 \times 5 \mathrm{ml}$ swing-out rotor at $30{ }^{\circ} \mathrm{C}$ was used. Immediately after centrifuging, the inoculum was removed and replaced with growth medium containing glucose $\left(5.4 \mathrm{mg} \mathrm{m}^{-1}\right)$. Infected monolayers were incubated at $35^{\circ} \mathrm{C}$ for 26 to $30 \mathrm{~h}$, rinsed in phosphate-buffered saline $\mathrm{pH} 7 \cdot 3$, fixed in methanol and stored until stained in May-Grunwald-Giemsa. The monolayers were examined microscopically at $300 \times$ to $500 \times$ magnification. The number of inclusions in a minimum of 30 microscope fields on each coverslip was noted and the infectivity of the inoculum calculated as i.f.u. $\mathrm{ml}^{-1}$ from the mean inclusion number per field and the ratio of the area of the internal cross-section of the Bijou bottle to that of the microscope field (at the magnification used).

Susceptibility of other cell cultures to gp-ic. In certain experiments, gp-ic infectivity for monolayers of unirradiated McCoy cells, BHK-2 I cells (from the Department of Virology, Medical School, Birmingham University) or HeLa cells (from Dr J. Wolstenholme, Department of Microbiology, Birmingham University) was examined. HeLa cells were grown in the medium used for McCoy cell culture with the substitution of $10 \%(\mathrm{v} / \mathrm{v})$ heated calf serum (Flow Laboratories) for foetal bovine serum and the addition of $\mathrm{I} \%$ ( $\mathrm{v} / \mathrm{v}$ ) nonessential amino acids (Gibco-Biocult). BHK-2I cells were grown in the Glasgow modification of Eagle's MEM containing $10 \%$ (v/v) tryptose phosphate broth (both from GibcoBiocult), and calf serum and antibiotics as for HeLa cells. Incubation conditions and cell passage and harvesting were as for McCoy cells. Coverslips received $10^{5}$ cells in the appropriate growth medium, but containing less $(2 \%, v / v)$ calf serum. After overnight incubation, monolayers were inoculated with gp-ic under the same conditions as for irradiated McCoy cells, except that centrifuging was continued for $2 \mathrm{~h}$; the gp-ic inoculum infected more than 


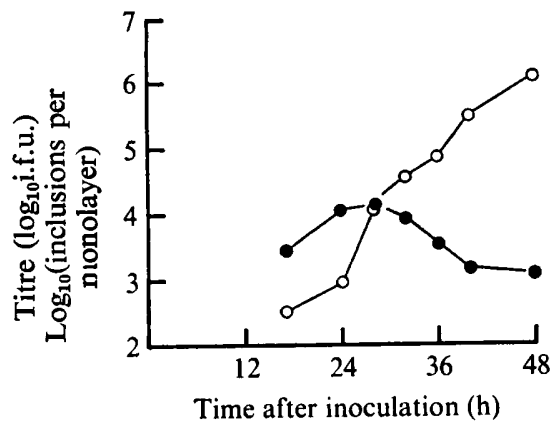

Fig. I. Growth of gp-ic in irradiated McCoy cell monolayers. The inoculum was centrifuged on to replicate monolayers. At intervals the medium from four monolayers was removed, pooled and titrated for released gp-ic infectivity as i.f.u. (O); the monolayers were fixed, stained and the numbers of inclusions counted $(\mathbf{O})$.

$90 \%$ of irradiated McCoy cells in parallel experiments. After centrifuging, the inoculum was removed and replaced with growth medium containing $2 \%(\mathrm{v} / \mathrm{v})$ calf serum. Monolayers were incubated for 28 and $36 \mathrm{~h}$ before fixation, staining and examination for the presence of inclusions.

\section{RESULTS}

\section{Development of $\mathrm{gp}$-ic inclusions}

No inclusions were detected in unirradiated McCoy or HeLa cell monolayers inoculated with gp-ic; occasional inclusions were seen in BHK-2I cells. However, glycogen-negative diffuse inclusions, typical of $C$. psittaci, were frequently observed in irradiated McCoy cells. The inclusions were evident by $\mathrm{I} 6 \mathrm{~h}$ after inoculation and grew in size thereafter. By $48 \mathrm{~h}$, the inclusions frequently occupied half to two-thirds of the cytoplasm of infected cells; but fewer inclusions were detected at 40 or $48 \mathrm{~h}$ than at $30 \mathrm{~h}$. Since the titration method was based on inclusion counts, it was necessary to define the time for visualizing the maximum number of inclusions. Replicate monolayers were therefore inoculated with gp-ic, incubated, and at intervals fixed, stained and examined for the presence of inclusions. Since it was possible that at 40 or $48 \mathrm{~h}$ some inclusions might have burst and released infective agent into the medium, supernatants from four monolayers were pooled and titrated for infectivity (Fig. I). There was an initial rise in the number of inclusions observed; inclusions at I $7 \mathrm{~h}$ were relatively difficult to discern. The maximum number of inclusions was observed at $28 \mathrm{~h}$ (in other experiments, no significant difference was found between 26 and $30 \mathrm{~h}$ ). The subsequent decline in the number of inclusions observed was accompanied by increasing amounts of gp-ic in the supernatant, suggesting that release of gp-ic was occurring. By $48 \mathrm{~h}$, only about $10 \%$ of the maximum number of inclusions remained, but these were very large; the monolayer was damaged, many cells had been lost and many of those that were infected were degenerating. In subsequent experiments, all inclusion counts were done on cells fixed between 26 and $30 \mathrm{~h}$ after inoculation.

\section{Titration conditions}

Inoculation medium. In preliminary experiments, no difference in the titre of gp-ic was found if either Eagle's MEM or Hanks balanced salts solution was used. A variable reduction in titre occurred if the inoculation medium did not contain protein, but there were no significant differences in titre when $10 \%(\mathrm{v} / \mathrm{v})$ foetal bovine serum, $1 \%(\mathrm{w} / \mathrm{v})$ bovine serum 


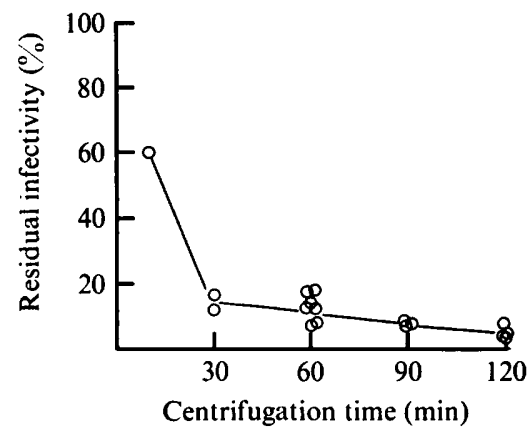

Fig. 2

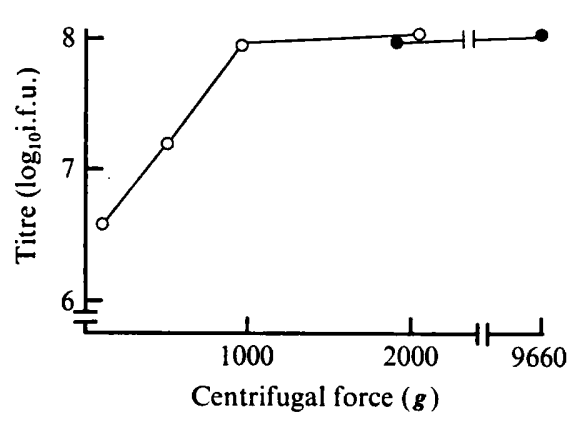

Fig. 3

Fig. 2. Disappearance of inoculum infectivity from the medium above monolayers with increasing centrifugation time. Monolayers inoculated with gp-ic were centrifuged at $2150 \mathrm{~g}$ at $35^{\circ} \mathrm{C}$ and, at intervals, supernatants were removed and assayed for residual infectivity.

Fig. 3. Change in titre with increasing centrifugal force. Monolayers inoculated with gp-ic were centrifuged with varying force for $60 \mathrm{~min}$ at $35^{\circ} \mathrm{C}$ in a Mistral $6 \mathrm{~L}$ centrifuge $(\mathrm{O})$, or at $30^{\circ} \mathrm{C}$ in a High speed 18 centrifuge $(\odot)$.

\section{Table I. Effect of temperature on the inoculum infectivity of monolayer supernatants}

Gp-ic inocula were centrifuged on to monolayers for $60 \mathrm{~min}$. The supernatants from four monolayers were then pooled and titrated for residual infectivity.

$\begin{array}{ccc}\begin{array}{c}\text { Centrifugal force } \\ (\mathrm{g})\end{array} & \begin{array}{c}\text { Temperature } \\ \left({ }^{\circ} \mathrm{C}\right)\end{array} & \begin{array}{c}\text { Inoculum in supernatant } \\ (\%)\end{array} \\ 2150 & 4 & 82 \\ 2150 & 20 & 32 \\ 2150 & 35 & 16 \\ 9660^{*} & 4 & 90\end{array}$

* This was a separate experiment, using a different centrifuge.

albumin or $10 \%(\mathrm{v} / \mathrm{v})$ calf serum were used. Subsequently, Hanks balanced salts solution containing $10 \%(\mathrm{v} / \mathrm{v})$ foetal bovine serum was used routinely.

Centrifugation time. Gp-ic was centrifuged on to replicate monolayers for different times. After each time, monolayers were removed and incubated to allow inclusions to develop, and medium supernatants were titrated for residual infectivity by centrifuging for $60 \mathrm{~min}$ on to fresh monolayers. Residual supernatant infectivity, as a percentage of the summed monolayer and supernatant titres at each time, was $\mathrm{I} I \cdot 7 \%$ and $3.2 \%$ after centrifuging for 60 and $120 \mathrm{~min}$, respectively (Fig. 2).

Centrifugal force. Forces from $100 \mathrm{~g}$ to $9660 \mathrm{~g}$ were applied. Increased centrifugal force raised the inoculum titre (Fig. 3); but increases in titre at forces above $1000 \mathrm{~g}$ were small.

Temperature. After centrifuging for I $\mathrm{h}$ at $4{ }^{\circ} \mathrm{C}$, more than $80 \%$ of the inoculum remained in the supernatant (Table I), even when a high centrifugal force $(9660 \mathrm{~g})$ was applied. At $35{ }^{\circ} \mathrm{C}$, this was reduced to $16 \%$.

\section{Condition of McCoy cells}

Irradiation dose. Neither varying the dose between 2500 and $7000 \mathrm{rad}$, nor varying the cell suspension concentration from $\mathrm{I} \times 10^{5}$ to $9.3 \times 10^{5}$ cells $\mathrm{ml}^{-1}$, resulted in significant differences in susceptibility to gp-ic infection. There was a tendency for some cells given 


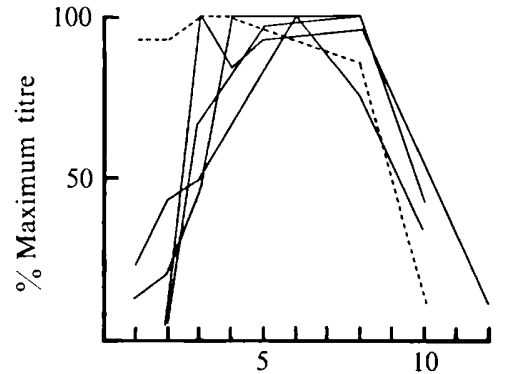

Age of irradiated monolayer (days)

Fig. 4

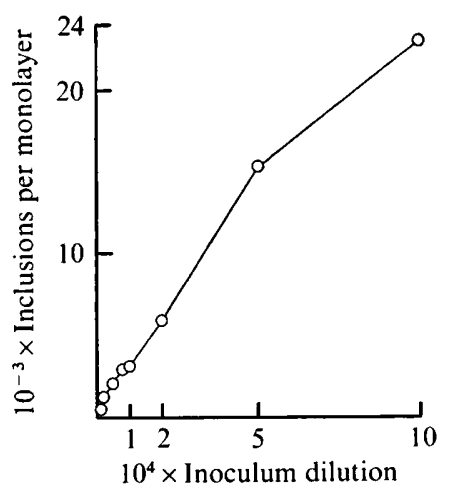

Fig. 5

Fig. 4. Change in monolayer susceptibility with increasing age after irradiation. Irradiated cells were seeded to give coverslip monolayers, and incubated at $35^{\circ} \mathrm{C}$. At intervals, monolayers were inoculated with a dilution of stock agent suspension. During each of five experiments (-, gp-ic; - -, MRC4f), the stock suspension was stored at $0^{\circ} \mathrm{C}$. Infectivity titres for cells of different ages within one experiment are expressed as a percentage of the maximum titre measured in that experiment.

Fig. 5. Increase in the number of inclusions with increasing inoculum concentration. Dilutions of a stock suspension of $\mathrm{gp}-\mathrm{ic}$ were centrifuged on to monolayers.

$2500 \mathrm{rad}$ to begin to proliferate after several days in culture. For this reason, cell suspensions were routinely given $5000 \mathrm{rad}$.

Susceptibility of cells after irradiation. Cells irradiated in suspension were tested between I and Io days after seeding out on to coverslips for their susceptibility to stock samples of gp-ic or MRC4f - a strain of $C$. trachomatis which readily infects both unirradiated and irradiated McCoy cells (Blyth \& Taverne, 1974). During this time, agent samples were kept at $0{ }^{\circ} \mathrm{C}$ without loss of infectivity as judged by assay in embryonated eggs. Susceptibility to gp-ic infection rose over the first 3 to 4 days after irradiation (Fig. 4), levelled out and then declined after 8 days; susceptibility to MRC4f varied little over the same period. The decline in susceptibility to both chlamydiae after 8 days was concomitant with the general decline in the health of the cells on the coverslips. Cells irradiated in suspension were more susceptible to gp-ic than cells irradiated as a monolayer by the method of Gordon et al. (I969), and also retained their healthy appearance for longer.

\section{Infectivity measurement}

Sensitivity. A purified yolk-sac preparation of gp-ic stored at $-70{ }^{\circ} \mathrm{C}$ for 6 months with a particle count (Reeve \& Taverne, 1962 ) of $\mathrm{I}^{1} 5 \times 10^{9}$ particles $\mathrm{ml}^{-1}$ titrated in cells at $2.45 \times$ $10^{8}$ i.f.u. $\mathrm{ml}^{-1}$, and in eggs at $6 \cdot \mathrm{I} \times \mathrm{IO}^{8} \mathrm{ELD}_{50} \mathrm{ml}^{-1}$.

Precision. Eighteen monolayers were inoculated with gp-ic such that less than $5 \%$ of the cells were infected. The mean count was 2.83 inclusions per field, with $3.25 \%$ standard error. In routine work, three coverslips were counted (standard error, $8 \%$ ).

Dose variation. From a stock suspension, eight dilutions containing between $2 \times 10^{3}$ and $\mathrm{I} \cdot 2 \times 10^{5}$ i.f.u. $\mathrm{ml}^{-1}$ were titrated. The number of inclusions formed was inversely proportional to the gp-ic dilution inoculated (Fig. 5). Departure from linearity with increasing dose could only be partly ascribed to multiple cell infection (25\% of the monolayer cells were infected at the highest inoculum). In routine work, assays were arranged so that generally I to $10 \%$ of the cells were infected. 
Table 2. Infectivity of different preparations of gp-ic, inoculated on to monolayers with and without centrifugation

Gp-ic samples were from growth in either the chick-embryo yolk sac, irradiated McCoy cells or guinea-pig conjunctiva. Monolayers were inoculated with gp-ic for 60 min at $35{ }^{\circ} \mathrm{C}$ either with $(2150 \mathrm{~g})$ or without centrifugation.

Origin of gp-ic

Yolk sac

Purified, yolk sac

McCoy cells

Guinea-pig conjunctival scrapings
Titre (i.f.u. $\mathrm{ml}^{-1}$ ) on monolayers

$\begin{array}{ccc}\text { Centrifuged (C) } & \text { Stationary (S) } & \text { C/S ratio } \\ 6.3 \times 10^{7} & 1 \cdot 8 \times 10^{4} & 3500 \\ 6.0 \times 10^{7} & 2.4 \times 10^{4} & 2500 \\ 1 \cdot 1 \times 10^{6} & 9.2 \times 10^{3} & 124 \\ 1 \cdot 2 \times 10^{4} & 1.6 \times 10^{2} & 75\end{array}$

\section{Characteristics of cell-grown gp-ic}

In early experiments, some infected cultures were examined either at $30 \mathrm{~h}$ or at $66 \mathrm{~h}$ after inoculation. In the $66 \mathrm{~h}$ cultures, there were about twice as many inclusions as at $30 \mathrm{~h}$. The majority of the inclusions at $66 \mathrm{~h}$ were relatively small, resembling those normally seen at $30 \mathrm{~h}$; about $10 \%$ of the inclusions were large, resembling those seen at $48 \mathrm{~h}$. The increased number of inclusions at $66 \mathrm{~h}$ and their 'young' appearance suggested that a second cycle of growth may have occurred in the cells, without centrifuging, and therefore that the progeny of the first growth cycle had altered properties. To test this, the supernatants from four $48 \mathrm{~h}$ infected cultures were pooled and inoculated on to six fresh monolayers; three of these were centrifuged and three were kept stationary at $35^{\circ} \mathrm{C}$ for $\mathrm{I} \mathrm{h}$. After $30 \mathrm{~h}$ incubation, inclusion counts were made and the ratio of the inclusions in centrifuged and stationary monolayers was calculated. Egg-grown gp-ic, egg-grown gp-ic after purification, and gp-ic taken from the conjunctiva of an infected guinea pig were also tested. Egg-grown gp-ic had substantially less capacity to infect cells in stationary incubation than either guinea-pig derived or McCoy-cell derived gp-ic (Table 2).

\section{DISCUSSION}

Our results confirm those of Treharne (I97I) that gp-ic grows in irradiated McCoy cells after centrifuging with a sensitivity of detection similar to that of eggs (particle:infectivity ratio in cells, $6 \cdot 1: I$; in eggs, $2 \cdot 4: 1$ ). One growth cycle appeared to be complete in about $30 \mathrm{~h}$ at $35^{\circ} \mathrm{C}$; this is similar to the growth cycle time of other C. psittaci strains in tissue culture (Litwin, 1959; Litwin et al., 1961). The optimum incubation time for counting inclusions was 26 to $30 \mathrm{~h}$; between these times the inclusions were large enough to be seen readily, but little release of agent from infected cells had occurred; detection of inclusions was also aided by the increase in cell size occurring after irradiation.

The very low infectivity of gp-ic for BHK-2I cells and the apparent insusceptibility of $\mathrm{HeLa}$ and unirradiated McCoy cells is in marked contrast to the equivalent sensitivity to TRIC agents of HeLa, BHK-2I and irradiated McCoy cells (Blyth \& Taverne, 1974). The $\mathrm{X}$-ray dose required to render McCoy cells susceptible to gp-ic did not appear to be critical. McCoy cells are more resistant to radiation than BHK-2I cells (Blyth \& Taverne, 1974) and L cells, but HeLa cells like McCoy cells, withstand 5000 rad (unpublished). There seems no reason to suppose that susceptibility to gp-ic induced by irradiation could not be achieved in these other cell lines with appropriate radiation dose. The increase in McCoy cell susceptibility, which stabilized 3 to 4 days after irradiation (Fig. 4), did not occur at the same time 
as enlargement of the cell; the latter was usually complete in 2 days. The lack of increase in susceptibility with age after irradiation, for MRC4f, is consistent with the inherent susceptibility of both irradiated and unirradiated McCoy cells to MRC4f infection (Blyth \& Taverne, 1974). The nature of the changes after irradiation which render McCoy cells susceptible to gp-ic is not known.

The application of increasing centrifugal force up to $1000 \mathrm{~g}$ enhanced inclusion titres; above this, the titres were not significantly different. Dependence on temperature and centrifugal force for maximal infectivity in cell cultures is common for many chlamydiae and has not so far been explained. Low infectivity titres in stationary incubation conditions, with substantial enhancement by centrifuging, as described here for gp-ic (Table 2), have been attributed to low adsorption (Reeve \& Taverne, 1967). Such chlamydiae evidently do not exhibit the temperature-independent adsorption shown by most other intracellular parasites.

The presence of a large proportion of the inoculum in the medium after centrifuging at $4{ }^{\circ} \mathrm{C}$ (Table I) implies that a temperature-dependent event occurs during the application of the centrifugal force which leads to irreversible association of particles with cells. This event might be particle uptake into the cells, or a temperature-dependent adsorption with particle entry occurring during subsequent incubation. Temperature-dependent adsorption has been reported for rickettsiae (Ramm \& Winkler, 1973), and the data of Friis (1972) imply that the chlamydial agent of meningopneumonitis showed temperature-dependent adsorption during entry into $\mathrm{L}$ cells, although without centrifuging. In view of the requirement for centrifugal force, as well as the temperature dependence, in gp-ic infection of McCoy cells, a more plausible explanation would be that centrifugation brings particles into close proximity with the McCoy cell membrane but that irreversible association occurs only as a result of temperature-dependent uptake. The latter would accord with the relatively long time needed for more than $95 \%$ of the inoculum to be removed from the medium.

Gp-ic passaged through McCoy cells or guinea-pig conjunctivae had a greater capacity to infect cells without centrifuging than had gp-ic derived from eggs (Table 2). Reducing the amount of contaminating yolk-sac material (purified versus unpurified gp-ic preparation) did not affect the result. The increased infectivity in stationary incubation of McCoy-cell or guinea-pig grown agent seems likely to depend on surface changes in gp-ic particles resulting in increased adsorption. Such adaptation could be due to selection or, conceivably, to some form of host-cell induced modification. This question is being investigated.

We are grateful to J. D. Treharne for much helpful advice at the start of this work.

\section{REFERENCES}

Blyth, W. A. \& Taverne, J. (1974). Cultivation of TRIC agents: a comparison between the use of BHK-2 I cells and irradiated McCoy cells. Journal of Hygiene, Cambridge 72, I 2 I-I 28.

Darougar, S., Jones, B. R., Kinnison, J. R., Vaughan-Jackson, J. D. \& Dunlop, E. M. C. (I972). Chlamydial infections, advances in the diagnostic isolation of Chlamydia, including TRIC agent, from the eye, genital tract and rectum. British Journal of Venereal Diseases 48, 416-420.

FRIIS, R. R. (I972). Interaction of L cells and Chlamydia psittaci: entry of the parasite and host responses to its development. Journal of Bacteriology 110, 706-721.

Gordon, F. B., Harper, I. A., Quan, A. L., Treharne, J. D., St. C. Dwyer, R. \& Garland, J. A. (1969). Detection of Chlamydia (Bedsonia) in certain infections of man. I. Laboratory procedures: comparison of yolk sac and cell culture for detection and isolation. Journal of Infectious Diseases 120, 451-462.

Litwin, J. (1959). The growth cycle of the psittacosis group of micro-organisms. Journal of Infectious Diseases ro5, I 29-160. 
Litwin, J., Officer, J. E., Brown, A. \& Moulder, J. W. (196I). A comparative study of the growth cycles of different members of the psittacosis group in different host cells. Journal of Infectious Diseases I09, 25 I-279.

Moore, J. E., Griffiths, M. S. \& Pearce, J. H. (I974). Chlamydial infection of conjunctival tissues in culture. British Journal of Experimental Pathology 55, 396-405.

Mount, D. T., Bigazzi, P. E. \& Barron, A. L. (1972). Infection of genital tract and transmission of ocular infection to newborn by the agent of guinea pig inclusion conjunctivitis. Infection and Immunity $\mathbf{5}$, $92 \mathrm{I}-926$.

Murray, E. S. (1964). Guinea pig inclusion conjunctivitis virus: I. Isolation and identification as a member of the psittacosis-lymphogranuloma-trachoma group. Journal of Infectious Diseases 114, I-I 2.

Murray, E. S., Charbonnet, L. T. \& MacDonald, A. B. (1973). Immunity to chlamydial infections of the eye. $I$. The role of circulatory and secretory antibodies in resistance to reinfection with guinea pig inclusion conjunctivitis. Journal of Immunology 110, I 5 I 8-I 525.

RAMM, L. E. \& WinKLER, H. H. (1973). Rickettsial hemolysis: adsorption of rickettsiae to erythrocytes. Infection and Immunity 7, 93-99.

Reeve, P. \& TAverne, J. (1962). A simple method for total particle counts of trachoma and inclusion blenorrhoea viruses. Nature, London I95, 923-924.

ReEve, P. \& TAVerne, J. (1967). Strain differences in the behaviour of TRIC agents in cell cultures. American Journal of Ophthalmology 63, I $167-1173$.

Treharne, J. D. (I97I). A comparison of microbiological techniques for the detection of gp-ic agent in the conjunctiva of infected guinea pigs. In Trachoma and Related Disorders, pp. 435-444. Edited yb R. L. Nicholls. Amsterdam: Excerpta Medica. 